\title{
Effectiveness in the Removal of Endotoxins and Microbiological Profile in Primary Endodontic Infections Using 3 Different Instrumentation Systems: A Randomized Clinical Study
}

\author{
Daiana Cavalli, DDS, MSc, * Cássia Cestari Toia, DDS, MSc, * \\ Esteban Isai Flores Orozco, DDS, MSc, * Rayana Duarte Kboury, DDS, \\ Flávia Goulart da Rosa Cardoso, DDS, MSc, PbD, * Marcelo Corrêa Alves, MSc, PbD, ${ }^{\dagger}$ \\ Cláudio Antônio Talge Carvalbo, DDS, MSc, PbD, ${ }^{*}$ and Marcia Carneiro Valera, DDS, MSc, PhD *
}

\section{Ahstract}

Introduction: This clinical study was conducted to correlate the microbiological profile and levels of endotoxins found in primary endodontic infection with the presence of clinical features and to evaluate the removal of microorganisms and endotoxins using rotary, reciprocating, and hybrid systems for biomechanical preparation. Methods: Thirty single root canals with primary endodontic infection were evaluated with signs and symptoms and were randomly divided into 3 groups according to the instrumentation system used $(n=10)$ as follows: rotary Mtwo instruments (VDW, Munich, Germany) with 8 files, the reciprocating Reciproc system (VDW) with a single file, and Genius hybrid instruments with 3 files (1 rotary and 2 reciprocating files) with irrigation using $24 \mathrm{~mL} 2.5 \%$ sodium hypochlorite. Samples were collected before (S1) and after instrumentation (S2) before being submitted to microbiological culture (colony-forming units $/ \mathrm{mL}$ ) and the checkerboard DNADNA hybridization test. Endotoxins were quantified using the limulus amebocyte lysate assay. Results: Microbiological culture showed statistical differences in the reduction of colony-forming units $/ \mathrm{mL}$ with all systems tested $(P<.05)$, but no statistical difference was found among the groups. The most frequently detected species were Capnocytophaga ochracea (53\%) and Fusobacterium nucleatum (53\%) at $\mathrm{S} 1$ and F. nucleatum (50\%) and Leptotrichia buccalis $(50 \%)$ at $\mathrm{S} 2$. As for the reduction of endotoxins at S2, Mtwo presented the best results $(95.05 \%)$ followed by the Genius (91.85\%) and Reciproc (64.68\%) groups, but no statistical difference was found among the groups. Previous pain, tenderness to percussion, and

presence of a sinus tract were associated with specific microorganisms $(P<.05)$. Conclusions: Signs and symptoms were correlated with microorganisms. Endodontic treatment was effective in reducing bacteria and endotoxins but was not capable of completely removing them from the root canal. (J Endod 2017;43:1237-1245)

\section{Key Words}

Checkerboard DNA-DNA hybridization, instrumentation, primary endodontic infection

In endodontic infections,

the aim of endodontic treatment is to decrease the number of bacterial cells and their products from the root canal and prevent new microorganisms from reaching the periapical region, thus promoting ideal conditions for healing. Therefore, biomechanical preparation is an important step of endodontic treatment, which is performed by using instruments and irrigants for cleaning and shaping the root canal (1).

The microbiota of root canal infections is highly diversified, including grampositive, gram-negative aerobic and mainly anaerobic microorganisms $(2,3)$. Gram-negative bacteria have several virulence factors such as proteases, fimbria, and lipopolysaccharides (LPS) (4). LPS, best known as an endotoxin, stimulates bone resorption by acting on the synthesis and release of cytokines, which in turn activates osteoclasts, thus being directly related to periapical lesions $(5,6)$. Thus, the removal of microorganisms and their by-products must be achieved by the action of the instruments onto the walls of the infected dentin, which leads to the mechanical displacement of the intracanal biofilm. Auxiliary chemical substances must also be used because they have an antimicrobial action that contributes to the removal of contaminated dentin, in

From the *Department of Restorative Dentistry, Endodontic Division, São Paulo State University (UNESP), Institute of Science and Technology, São José dos Campos, SP, Brazil; and "Superior School of Agriculture "Luiz de Queiroz" Technical Section of Information Technology, University of São Paulo, São Paulo, Brazil.

Address requests for reprints to Dr Marcia Carneiro Valera, Endodontic Division, Department of Restorative Dentistry, São José dos Campos Dental School, State University of São Paulo, UNESP, Eng Francisco José Longo, 777, São José dos Campos, São Paulo, CEP 12245-000, Brazil. E-mail address: marcia@fosjc.unesp.br 0099-2399/\$ - see front matter

Copyright $\odot 2017$ Published by Elsevier Inc. on behalf of American Association of Endodontists. http://dx.doi.org/10.1016/j.joen.2017.03.032 
addition to acting on the microorganisms and their by-products present inside the dentinal tubules (7).

Instrumentation systems using nickel-titanium (NiTi) rotary files have evolved over time, leading to new designs and faster and easier techniques, not only preserving the original shape of the root canal but also minimizing the risk of errors (8). Several instrumentation systems can be used to achieve this goal. The Mtwo rotary system (VDW, Munich, Germany), which consists of a series of NiTi instruments used in continuous rotation motion, includes a large file to prevent the accumulation of debris in the apical region (9). The reciprocating single file was introduced to increase fracture resistance because it uses thermo-treated files made of standard NiTi alloy (10). The Reciproc files (VDW) were developed based on reciprocating motions at $150^{\circ}$ counterclockwise rotations to cut dentin and at $30^{\circ}$ clockwise rotations to release the file from the canal wall (11). The Genius hybrid system (Ultradent, South Jordan, UT) has been developed recently to associate rotary and reciprocating techniques. This system is composed of 1 rotating file used to enlarge the canal entrance, whereas 2 reciprocating files are used to prepare the root canal with $170^{\circ}$ counterclockwise rotations and $50^{\circ}$ clockwise rotations. To our knowledge, however, there is no in vivo study in the literature investigating the benefits, especially the antimicrobial activity on microorganisms and endotoxins, of hybrid systems associated to sodium hypochlorite ( $\mathrm{NaOCl}$ ) compared with rotary and reciprocating systems.

Thus, the present randomized clinical study aimed to correlate the microbiological profile and levels of endotoxin found in primary endodontic infection with the presence of clinical signs and symptoms as well as to evaluate the removal of microorganisms and endotoxins using 3 different techniques for biomechanical preparation, namely, rotary Mtwo, reciprocating Reciproc, and hybrid Genius systems.

\section{Patient Selection}

\section{Materials and Methods}

Thirty patients attending the endodontic clinic at the São José dos Campos Dental School (São Paulo State University), São José dos Campos, São Paulo, Brazil, with a diagnosis of pulp necrosis and radiographically visibly periradicular lesions (symptomatic and asymptomatic) were included in the present study. Criteria for inclusion were as follows: only single-rooted teeth with primary endodontic infection confirmed by a negative response to sensibility tests and radiographic evidence of apical periodontitis. Patients with periodontal pockets deeper than $4 \mathrm{~mm}$, previous endodontic treatment, antibiotic and antifungal therapy in the past 3 months, and teeth that could not be isolated with a rubber dam were excluded from this study. Clinical signs and symptoms such as previous pain, tenderness to percussion and palpation, presence of a sinus tract, and exudate were recorded. The local research ethics committee approved the protocol describing the sample collection for this investigation, and all the voluntary patients signed an informed consent form.

\section{Sample Collection}

All the steps of this dental intervention were performed under aseptic conditions. Files, instruments, and all the materials used in this study were treated with Co-60 gamma radiation $(20 \mathrm{kGy}$ for 6 hours) for sterilization and elimination of preexisting endotoxins (CBE; Empresa Brasileira de Radiação, Cotia, SP, Brazil). Patients were anesthetized, the teeth were isolated with a rubber dam, and the crown and surrounding structures were disinfected using sterile swabs moistened with $30 \% \mathrm{H}_{2} \mathrm{O}_{2}$ (v/v) for 30 seconds followed by $5.25 \%$
$\mathrm{NaOCl}$ for the same period of time and 5\% sodium thiosulfate for inactivation (6).

Two-stage access cavity preparation was performed without the use of water spray but under manual irrigation with sterile/apyrogenic saline solution and using a sterile/apyrogenic high-speed diamond bur. The first stage was performed to promote a major removal of contaminants, including carious lesions and restoration. In the second stage before entering the pulp chamber, the access cavity was disinfected after isolation with a rubber dam. All procedures were performed aseptically.

Immediately before biomechanical preparation, an initial sample (S1) was collected from the root canal to serve as the baseline. For endotoxin sampling, sterile/apyrogenic paper points (size \#15; Dentsply Maillefer, Ballaigues, Switzerland) were introduced into the full length of the canal, which was determined radiographically, and retained in position for 60 seconds. Immediately after, the sample was placed in a pyrogen-free glass container and immediately suspended in $1 \mathrm{~mL}$ limulus amebocyte lysate (LAL) water according to the endotoxin dosage using the kinetic chromogenic LAL (Lonza, Walkersville, MD) assay. This sampling procedure was repeated with 3 paper points, which were then pooled in a sterile tube containing $1 \mathrm{~mL}$ VMGA III transport medium (12) for microbial analysis.

After the first sampling (S1), the biomechanical instrumentation was performed with $2.5 \% \mathrm{NaOCl}$. The working length (WL) was determined by using an apex locator (RomiApex A-15; Romidan Dental Solution, Kiryat-Ono, Israel) and confirmed radiographically using the digital RX (Micro Imagem, Indaiatuba, SP, Brazil) set $1 \mathrm{~mm}$ short of the apical foramen. A \#15 hand K-file was used to initially enlarge the canal. The teeth were randomly divided into 3 groups $(n=10)$ according to the instrument system used for root canal preparation.

Mtwo Rotary System Group. The first group was instrumented using Mtwo files (Romibras LTDA, Rio de Janeiro, Brazil) adapted to an electric motor (VDW) in rotary movement. The files were used as follows: 0.04 taper size \#10 instrument, 0.05 taper size \#15 instrument, 0.06 taper size \#20 instrument, 0.06 taper size \#25 instrument, 0.07 taper size \#25 instrument, 0.05 taper size \#30 instrument, 0.04 taper size \#35 instrument, and 0.04 taper size \#40 instrument, which correspond to kits 701 and 702 . The instrumentation was performed in a gentle in-and-out motion, taking the file to the WL. Irrigation was performed with $3 \mathrm{~mL} 2.5 \% \mathrm{NaOCl}$ solution between each file, totaling $24 \mathrm{~mL}$ at the end of the instrumentation.

Reciproc Reciprocating System Group. The second group was instrumented with 1 single file from the Reciproc System (VDW) adapted to an electric motor (VDW) in reciprocation movement. The file was used as follows: 0.06 taper size \#40 instrument. Instrumentation was performed according to the crown-down technique (ie, coronal, medium, and apical) with irrigation with $8 \mathrm{~mL} 2.5 \% \mathrm{NaOCl}$ solution for each third, totaling $24 \mathrm{~mL}$ at the end of the instrumentation.

Genius Hybrid System Group. The third group was instrumented using the Genius hybrid system (Ultradent) adapted to an electric motor (EVOS, Ultradent) as follows: 0.08 taper size \#30 instrument to amplify the entrance of the canal in rotary motion followed by 0.04 taper size \#25 instrument and 0.04 taper size \#40 instrument at the WL in a reciprocation movement. Irrigation was performed with $8 \mathrm{~mL} 2.5 \%$ $\mathrm{NaOCl}$ solution between each file, totaling $24 \mathrm{~mL}$ irrigation solution.

Foraminal cleaning was performed in all teeth with a \#30 K-file along the tooth length at the end of biomechanical preparation. Then, each root canal was irrigated with $5 \mathrm{~mL} 5 \%$ sodium thiosulfate, and the final irrigation was performed with $10 \mathrm{~mL}$ sterile physiological saline. Next, the second sampling (S2) was performed as previously described, with the samples being submitted to endotoxin analysis, microbiological culture, and the checkerboard test. 
After the second sampling, the root canals were flooded with $17 \%$ EDTA solution (Inodon, Porto Alegre, RS, Brazil) during a 5-minute period. Next, a final rinse with $10 \mathrm{~mL}$ sterile/pyrogenic saline solution was performed before the root canals were dried with sterile paper points. The root canals were then filled with a freshly prepared paste of calcium hydroxide (Biodinâmica Química e Farmacêutica LTDA, Paraná, Brazil) and sterile saline solution at a ratio of 1:1. The paste was inserted into the root canals with the aid of a Lentulo spiral filler (Dentsply/Maillefer Instruments AS, Ballaigues, Switzerland). Care was taken to properly fill the root canal with the calcium hydroxide paste without any radiographically visible air bubbles. The teeth were then sealed with a layer of Coltosol (Vigodent, Rio de Janeiro, RJ, Brazil) and temporarily restored with glass ionomer cement (SS White Artigos Dentários Ltda, Rio de Janeiro, Brazil).

After 14 days with intracanal medication, the patients were again submitted to anesthesia, and the operatory field was isolated and disinfected, including removal of the temporary restoration and intracanal medication using a \#30 K-file (Dentsply/Maillefer Instruments AS). Next, the root canals were irrigated with $10 \mathrm{~mL}$ sterile saline solution. Those patients who had not reported pain and whose root canals had no odor and humidity were obturated 2 weeks later by using the single-cone obturation technique and AH Plus (Dentsply DeTrey $\mathrm{GmbH}$, Konstanz, Germany) as a sealer. Because instrumentation was performed with rotary and reciprocating systems, it is possible to use 1 single gutta-percha point corresponding to the chosen file and its particular conicity.

\section{Eulture Procedure}

The transport media containing the root canal samples were thoroughly shaken for 60 seconds (Vortex; Marconi, Piracicaba, São Paulo, Brazil). Serial 10-fold dilutions were made up to $10^{-3}$. Fifty microliters of the serial dilutions was plated onto $5 \%$ defibrinated sheep blood fastidious anaerobe agar (Lab M, Bury, UK) using sterile plastic spreaders to culture nonselective obligate anaerobes and facultative anaerobes. The plates were incubated at $37^{\circ} \mathrm{C}$ in an anaerobic atmosphere for up to 14 days. After this period, colony-forming units were visually quantified for each plate.
Microbiological Analysis: Checkerboard DNA-DNA

\section{Hybridization}

Three hundred microliters of VMGA containing the root canal samples was transferred to a sterile tube before centrifugation at $8000 \mathrm{rpm}$ for 5 minutes. The supernatant was then discarded and the pellet resuspended in $150 \mathrm{~mL}$ Tris-EDTA buffer $(10 \mathrm{mmol} / \mathrm{L}$ tris [hydroxymethyl] aminomethane [Tris]-HCl, $1 \mathrm{mmol} / \mathrm{L}$ EDTA, $\mathrm{pH}=7.6$ ). Next, $100 \mathrm{~mL} 0.5 \mathrm{~mol} / \mathrm{L} \mathrm{NaOH}$ was added to each tube, and the samples were frozen at $20^{\circ} \mathrm{C}$ until they were processed.

The presence, levels, and proportions of 40 bacterial species (Table 1) were determined by the checkerboard DNA-DNA hybridization method described by Socransky et al (13). The DNA probes were prepared using the DIG DNA Labeling Kit (Roche Diagnostics, Indianapolis, IN) and frozen until use. Next, the samples were boiled for 10 minutes, and $800 \mathrm{~mL} 5 \mathrm{~mol} / \mathrm{L}$ ammonium acetate was added in order to promote bacterial lyses and consequent suspension of DNA in solution. A nylon membrane $(15 \times 15 \mathrm{~cm})$ with a positive charge (Amersham Biosciences, Chicago, IL) was placed in a MiniSlot 30 apparatus (Immunetics, Cambridge, MA) before $1000 \mathrm{~mL}$ of each suspension was placed into the extended slots and fixed to the membrane by baking it at $120^{\circ} \mathrm{C}$ for 20 minutes. Each membrane had 28 samples, with the last 2 channels of the MiniSlot 30 being reserved for the placement of controls, containing a mixture of microbial species to be investigated by DNA probes at 2 concentrations (ie, $10^{5}$ and $10^{6}$ ) of bacterial cells. A Miniblotter 45 apparatus (Immunetics) was used to hybridize the digoxigenin-labeled whole-genomic DNA probes perpendicular to the lanes of the clinical samples. Bound probes were detected with the use of phosphatase-conjugated antibodies to digoxigenin and chemiluminescence (CDP-Star Detection Reagent; GE Healthcare Limited, Little Chafont, UK). The membranes were left under a radiographic film (AGFA-IBF; Duque de Caxias, Rio de Janeiro, Brazil) for almost $60 \mathrm{mi}-$ nutes. The films were processed, and each probe produced a certain type of signal, which was visually compared with those produced by the probes in the 2 controls containing $10^{5}$ and $10^{6}$ bacterial cells. The signals were coded into 6 different classes in relation to the following count levels: 0 : not detected, $1:<10^{5}$ cells, 2 : nearly $10^{5}$ cells, 3: between $10^{5}$ and $10^{6}$ cells, and 4: nearly $10^{6}$ cells.

TABLE 1. Bacterial Strains Used for the Development of DNA Probes

\begin{tabular}{|c|c|c|c|c|c|}
\hline Species & Strain & Gram & Species & Strain & Gram \\
\hline Actinomyces israelli & 12102 & + & Leptotrichia buccalis & 14201 & - \\
\hline Actinomyces odontolyticus & 17929 & + & Neisseria mucosa & 19696 & - \\
\hline Actinomyces oris & 43146 & + & Parvimonas micra & 33270 & + \\
\hline $\begin{array}{l}\text { Agregatibacter } \\
\text { Actinomycetemcomitans }(\mathrm{a}+\mathrm{b})\end{array}$ & 43718 e 29523 & - & Porphyromonas endodontalis & 35406 & - \\
\hline Campylobacter gracilis & 33236 & - & Porphyromonas gingivalis & 33277 & - \\
\hline Campylobacter rectus & 33238 & - & Prevotella intermédia & 25611 & - \\
\hline Campylobacter showae & 51146 & - & Prevotella melaninogenica & 25845 & - \\
\hline Capnocytophaga gingivalis & 33624 & - & Prevotela nigrescens & 33563 & - \\
\hline Capnocytophaga ochracea & 33596 & - & Propionybacterium acnes $(\mathrm{I}+\mathrm{II})$ & 11827 e 11282 & + \\
\hline Capnocytophaga sputigena & 33612 & - & Selemonas noxia & 43541 & - \\
\hline Eikenella corrodens & 23837 & - & Streptococcus anginosus & 33397 & + \\
\hline Enterococcus faecalis & 29212 & + & Streptococcus constellatus & 27823 & + \\
\hline Enterococcus faecium & 6569 & + & Streptococcus gordonii & 10558 & + \\
\hline Eubacterium nodatum & 33099 & + & Streptococcus intermedius & 27335 & + \\
\hline Eubacterium saburreum & 33271 & + & Streptococcus mitis & 49456 & + \\
\hline $\begin{array}{l}\text { Fusobacterium nucleatum ssp } \\
\text { nucleatum }\end{array}$ & 25586 & - & Streptococcus sanguinis & 10556 & + \\
\hline $\begin{array}{l}\text { Fusobacterium nucleatum ssp } \\
\text { polymorphum }\end{array}$ & 10953 & - & Tannerella forsythia & 43037 & - \\
\hline $\begin{array}{l}\text { Fusobacterium nucleatum ssp } \\
\quad \text { vincentii }\end{array}$ & 49256 & - & Treponema denticola & B1 & - \\
\hline Fusobacterium periodonticum & 33693 & - & Treponema socranskii & S1 & - \\
\hline Gemella morbillorum & 27824 & + & Veillonela parvula & 10790 & - \\
\hline
\end{tabular}




\section{Quantification of Endotoxins [LPSs]: Kinetic Chromogenic Lal Assay}

The kinetic chromogenic LAL assay (Lonza) was used for the quantification of endotoxins. The Escherichia coli endotoxin was used as the standard. A positive control (root canal sample contaminated with a known amount of endotoxin) was included for each sample to determine the presence or absence of interfering agents. For the test, $100 \mu \mathrm{L}$ apyrogenic water (reaction blank), 5 standard endotoxin solutions $(0.005-50$ endotoxin units $/ \mathrm{mL}$ ), root canal samples, and positive controls (each root canal sample contaminated with a known concentration of endotoxin [10 endotoxin units $/ \mathrm{mL}$ ]) were added to a 96-well apyrogenic plate. The tests were performed in quadruplicate. The plate was incubated at $37^{\circ} \mathrm{C} \pm 1^{\circ} \mathrm{C}$ for 10 minutes in a kinetic-QCL reader (Lonza, Walkerville, MI), which was coupled to a microcomputer using WinKQCL software (Lonza). Next, $100 \mu \mathrm{L}$ chromogenic reagent was added to each well. After the beginning of the kinetic test, the software continuously monitored absorbance at $405 \mathrm{~nm}$ in each microplate well and automatically calculated the $\log / \log$ linear correlation between the reaction time of each standard solution and the corresponding endotoxin concentration.

\section{Statistical Analysis}

The resulting data were entered into Excel (Microsoft, Redmond, WA) spreadsheets, and all calculations were performed using the SAS System (SAS Institute Inc, Cary, NC). The Tukey test was used to assess the effect of biomechanical preparation on the reduction of endotoxins and microorganisms in culture. Checkerboard analysis was also performed throughout the different stages of endodontic treatment. The 1-sided Fisher exact test was used to verify the positive association between the number of different bacterial species and the presence of clinical signs and symptoms.

\section{Culturing Procedure}

\section{Results}

Bacteria were found in 28 initial samples of the 30 root canals investigated. The results of the analysis (colony-forming units $/ \mathrm{mL}$ ) show that the biomechanical procedure was effective in reducing the number of cultivable bacteria, with statistical difference being observed between S1 and S2 $(P<.05)$. However, no statistically significant difference was found between the Mtwo (99.96\%), Reciproc (97.51\%), and Genius (99.93\%) systems regarding the median percentage values for the reduction of cultivable bacteria. In addition, root canals free of cultivable bacteria were found in 5 of 10,2 of 10 , and 7 of 10 cases using, respectively, the Mtwo, Reciproc, and Genius systems.

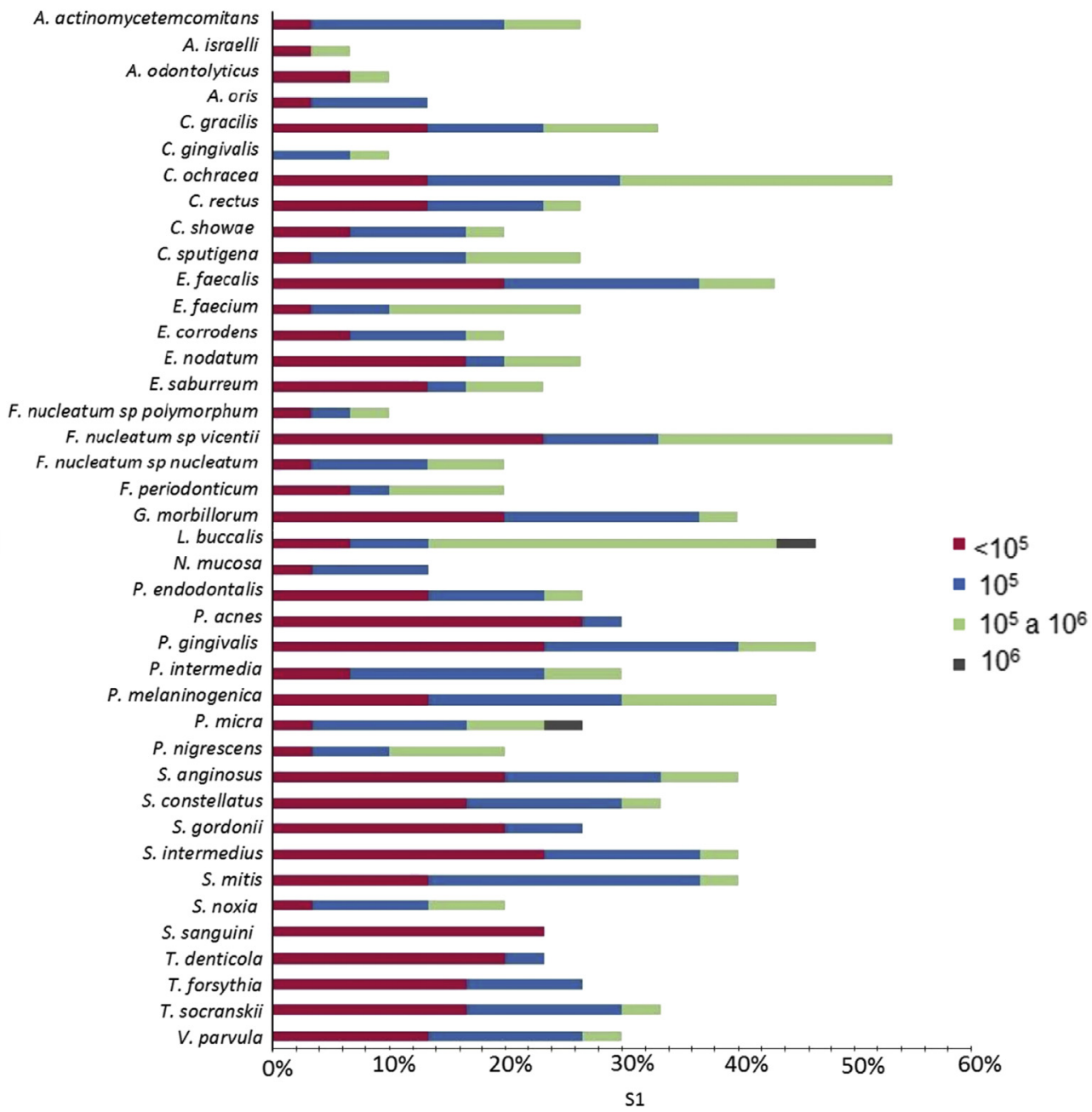

Figure 1. The frequency and DNA concentration of individual bacterial species investigated before root canal treatment (S1). The total length of each bar indicates the percentage of positive samples. Different colors within each bar indicate the percentage of samples containing different concentrations of bacterial DNA. 


\section{Microbiological Analysis: Checkerboard DNA-DNA Hybridization}

The presence of bacterial DNA was detected in all root canals investigated, showing bacterial signals for at least 1 of the 40 DNA bacterial probes tested. At $\mathrm{S} 1$, the mean number of bacterial species per root canal was 11.3 (range, 1-36), and the most prevalent bacterial species detected were Capnocytophaga ochracea (53.33\%), Fusobacterium nucleatum ssp vicentii (53.33\%), Porphyromonas gingivalis (46.67\%), and Leptotrichia buccalis (46.67\%). At S2, the mean number of bacterial species was 10.1 (range, 1-28), and the most prevalent bacterial species detected were $F$. nucleatum ssp vicentii $(50 \%)$, L. buccalis $(50 \%)$, and P. gingivalis (46.70\%). The frequency and DNA concentration of individual bacterial species investigated at S1 and S2 are shown in Figures 1 and 2, respectively. There was no statistical difference between S1 and S2 $(P>.05)$.

By correlating the Mtwo, Reciproc, and Genius groups, the mean number of bacterial species at $\mathrm{S} 1$ was 17 (range, 5-36),
10.2 (range, 1-18), and 6.7 (range, 2-10), respectively (Table 2). At S2, it was 12.4 (range, 2-28), 8.5 (range, 1-21), and 9.4 (range, 5-17). Figure 3 shows the difference between the groups regarding the prevalence of microorganisms at different stages of endodontic treatment.

There was no statistical difference between the 3 groups (ie, Mtwo, Reciproc, and Genius) regarding the removal of microorganisms from the root canal. However, a statistically significant difference was observed between the Mtwo and Genius groups in all 3 samples regarding the mean number of bacterial species.

\section{Quantification of Endotoxins [LPSs): Kinetic Chromogenic LAL Assay}

Although endotoxin was found in all samples, at S2 a significant reduction in the number of endotoxins was observed in all groups $(P<.05)$ but with no differences among the groups. Mtwo $(95.05 \%)$ showed the best result followed by Genius (91.85\%) and

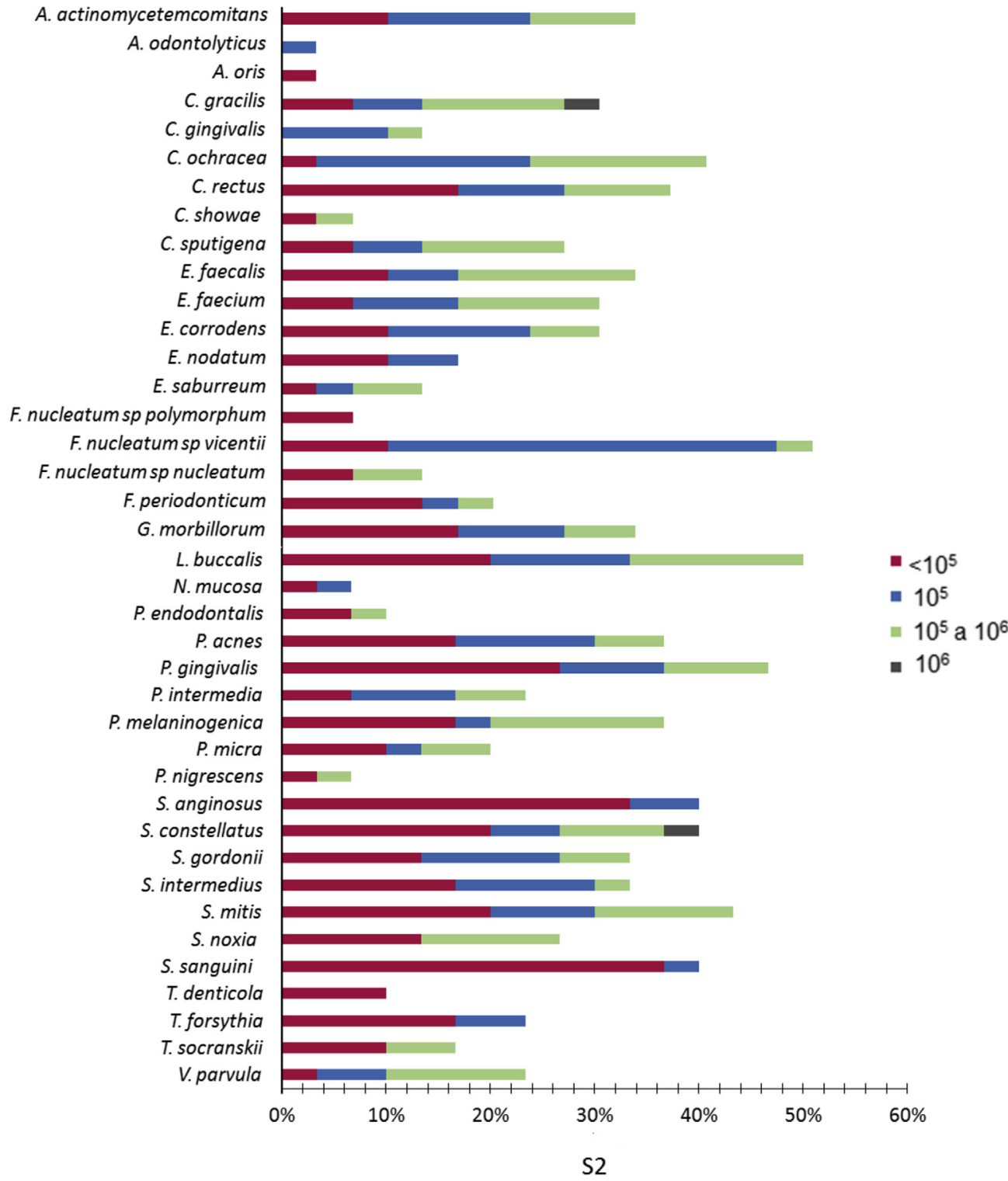

Figure 2. The frequency and DNA concentration of individual bacterial species investigated after root canal treatment (S2). The total length of each bar indicates the percentage of positive samples. Different colors within each bar indicate the percentage of samples containing different concentrations of bacterial DNA. 
TABLE 2. The Mean Number of Microbial Species Found in Each Group at Different Stages of Endodontic Treatment

\begin{tabular}{lcc}
\hline Groups & S1 (Mean-range) & S2 (Mean-range) \\
\hline Mtwo & $17(5-36)^{\mathrm{Aa}}$ & $12.4(2-28)^{\mathrm{Aa}}$ \\
Reciproc & $10.2(1-18)^{\mathrm{ABa}}$ & $8.5(1-21)^{\mathrm{ABa}}$ \\
Genius & $6.7(2-10)^{\mathrm{Ba}}$ & $9.4(5-17)^{\mathrm{Ba}}$ \\
\hline
\end{tabular}

Uppercase superscript letters indicate different rows and lowercase superscript letters different columns.

Reciproc $(64.68 \%)$ regarding the median percentage values for the reduction of endotoxin levels.

\section{Associations with Signs and Symptoms}

The statistical test showed the presence of previous pain related to Prevotella nigrescens $(P<.05)$. Tenderness to percussion was related to $P$. gingivalis, Veillonella parvula, Capnocytophaga sputigena, $P$. nigrescens, and Eubacterium saburreum $(P<.05)$. The presence of a sinus tract was related to Eikenella corrodens, Parvimonas micra, Campylobacter showae, and E. saburreum $(P<.05)$. A sinus tract was also associated with gram-positive microorganisms and facultative anaerobes $(P<.05)($ Table 3$)$.

\section{Discussion}

The present clinical study evaluated the microbial profile in the different steps of endodontic treatment by comparing 3 different systems, namely, rotary (Mtwo), reciprocating (Reciproc), and hybrid (Genius) associated with $2.5 \% \mathrm{NaOCl}$, showing that all 3 systems behaved similarly in the removal of microorganisms from root canals.

Microbiological culture analysis revealed the presence of cultivable microorganisms in $93.33 \%$ of the initial samples (S1). After biomechanical preparation (S2) using different instrumentation systems, the number of cultivable anaerobic bacteria decreased to 99.96\% (Mtwo), 97.51\% (Reciproc), and 99.93\% (Genius) but without differences between the instrumentation systems tested. These results corroborate the findings reported by previous studies, which showed that biomechanical preparation, independently of the instrumentation system used, reduces the microbial load present in the root canal $(14,15)$. When the number of root canals with cultivable bacteria was evaluated at S2 (ie, after biomechanical preparation), it was observed that $80 \%$ of the root canals were positive for the presence of cultivable bacteria in the Reciproc group. In the Mtwo group, $50 \%$ of the root canals were positive for the presence of cultivable bacteria, revealing that the instrumentation technique may contribute to reducing the bacterial load from root canal despite not being able to completely eliminate these microorganisms.

Data from checkerboard DNA-DNA hybridization revealed that all initial samples (S1) had a mean of 11.3 species per root canal, which supports the polymicrobial nature of the primary endodontic infections (16). The most prevalent microorganisms in the first sample were $C$. ochracea (53.33\%), F. nucleatum (53.33\%), P. gingivalis (46.67\%), and L. buccalis (46.67\%). According to previous studies, which also reported a high prevalence of Capnocytophaga, Porphyromonas, and Fusobacterium, these microorganisms are usually associated with primary endodontic infections (16-18).

C. ochracea is a gram-negative bacterium frequently associated with severe and advanced periodontal disease. Periodontal studies report that bacteria involved in periodontal disease may reach the bloodstream and cause bacteremia, especially in immunocompromised patients $(19,20)$. However, little is known about this possibility in endodontics. F. nucleatum, which was also highly detected in our study, was present in the root canals independently of the treatments performed. This microorganism is known by its adhesive features, which coaggregate several bacterial species and facilitate the interaction among them. This explains the recurrent association of $F$. nucleatum with biofilm formation and its persistence in large amounts after biomechanical preparation $(21,22)$. Based on this, $P$. gingivalis, another highly detected bacterium in the present study, possibly interacts with $F$. nucleatum, which is a facilitator of its colonization (23). P. gingivalis is also a gram-negative strictly anaerobic bacterium, which presents several virulence factors, such as the presence of fimbriae and extracellular proteins related to biofilm formation. In addition, by-products of these bacteria are related to several stages of periapical disease (24) and systemic disease (25).

At S1, the Mtwo group presented a mean of 17 bacterial species, which statistically differed from that of the Genius group (mean of 6.7). This difference may have occurred because the present study was randomized, and like any other ex vivo study, there are some uncontrollable variables specific to each patient (26). After biomechanical preparation (S2), all the groups were compared with their respective initial sample (S1); however, no statistical difference was observed in the groups.

Checkerboard DNA-DNA hybridization is a molecular method highly recommended to determine the bacterial profile in polymicrobial infections. The simultaneous identification of multiple bacteria in several samples represents a great advantage of this method. Moreover, this technique is rapid and accurate in providing quantitative data on noncultivable microorganisms from DNA strains (13). Although this technique was first described by Socransky et al (13) in periodontal studies, checkerboard DNA-DNA hybridization represents an important methodology in endodontics regarding the development of better and more precise therapies.

By analyzing the data from the checkerboard DNA-DNA hybridization methodology, it is possible to observe that there was no statistical difference between the samples (S1 and S2) or between the groups (Mtwo, Reciproc, and Genius) when the number of bacterial species was evaluated. It is also observed that in the Genius group, the number of species/root canals increased at $\mathrm{S} 2$ but without statistical differences in relation to $\mathrm{S} 1$ because the molecular method can lead to the detection of bacteria that are no longer viable. However, the microbiological culture method revealed a notable statistical difference in the reduction of cultivable bacteria between the samples ( $\mathrm{S} 1$ and $\mathrm{S} 2$ ) in all groups with a reduction of $99.93 \%$ of cultivable bacteria in the Genius group. Therefore, it is important to point out that microbiological culture has the ability to detect only viable and cultivable bacteria but fails in identifying uncultivable bacteria. On the order hand, the molecular method is able to detect and quantify not only cultivable bacteria but also bacteria that are no longer viable and those of species difficult or impossible to culture. Moreover, probably because of the prolonged transportation of samples during the culturing procedure, some critical bacteria may be underestimated in microbiological culture (27). Therefore, the results obtained by microbiological culture and DNA probes may differ; nevertheless, they provide complementary results

Endotoxins were detected in all teeth and samples, and after biomechanical preparation (S2), there was a significant reduction in the endotoxin levels in all groups compared with the initial sample (S1). With regard to the instrumentation systems used in the present study, the rotary one produced the greatest reduction of endotoxin levels after biomechanical preparation followed by the hybrid and reciprocating systems. The rotary system used consists of multiinstruments with several conicities. Although the amount of irrigation solution was standardized in the 3 groups evaluated, in the rotary system group the volume of irrigants was subdivided after each 
s1

A. actinomycetemcomitans

A. israelli

A. odontolyticus

A. oris

C. gingivalis

C. gracilis

C. ochracea

C. rectus

C. showae

C. sputigena

E. corrodens

E. faecalis

E. faecium

E. nodatum

E. saburreum

F. nucleatum $s p$ nucleatum

F. nucleatum sp.

F. nucleatum $s p$ vicentii

F. periodonticum

G. morbillorum

L. buccalis

N. mucosa

P. acnes

$P$. endodontalis

P. gingivalis

P. intermedia

P. melaninogenica

P. micra

P. nigrescens

S. anginosus

S. constellatus

S. gordonii

S. intermedius

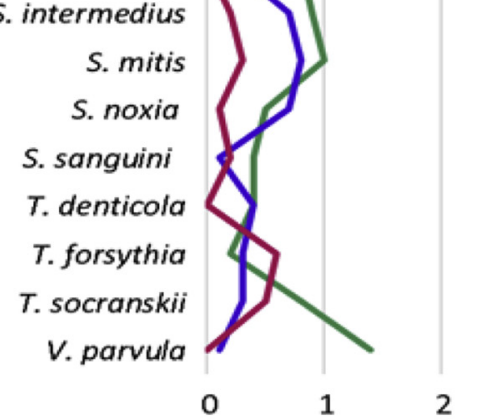

Mtwo s2

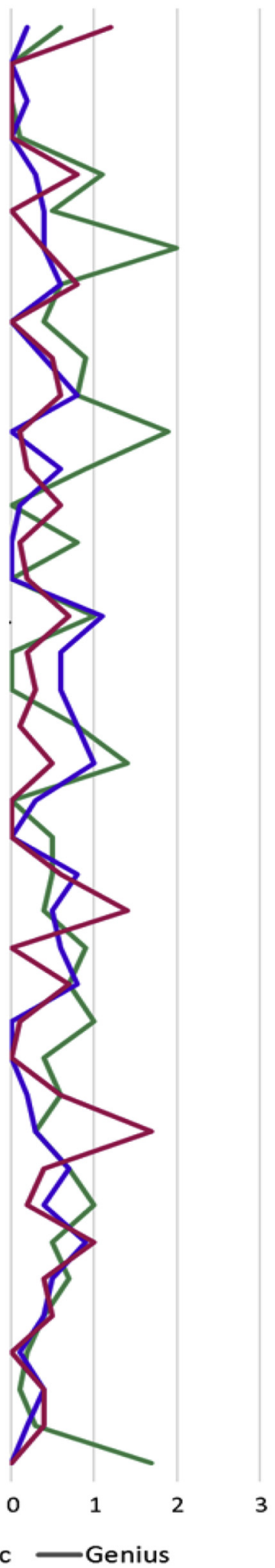

Figure 3. The difference in score between the mean value of bacterial load balanced by the number of patients in the 2 samples performed during the endodontic treatment.

file, which may have favored the root canal cleaning, even though no significant difference was found compared with the other groups. Marinho et al (28) also compared the reduction of endotoxins after biomechanical preparation with the Mtwo and Reciproc systems, reporting no significant differences between them (a finding corroborating the present study). Additionally, the reciprocating system 
TABLE 3. Positive Associations between Signs and Symptoms

\begin{tabular}{|c|c|c|}
\hline \multirow[b]{2}{*}{$\begin{array}{l}\text { Signs and } \\
\text { symptoms }\end{array}$} & \multicolumn{2}{|c|}{ Positive associations } \\
\hline & $\begin{array}{l}\text { Microbial } \\
\text { features }\end{array}$ & Species \\
\hline Previous pain & - & Prevotella nigrescens \\
\hline $\begin{array}{l}\text { Tenderness to } \\
\text { percussion }\end{array}$ & - & $\begin{array}{l}\text { Porphyromonas gingivalis } \\
\text { Veillonella parvula } \\
\text { Capnocytophaga } \\
\text { sputigena } \\
\text { Prevotella nigrescens } \\
\text { Eubacterium } \\
\text { saburreum }\end{array}$ \\
\hline Sinus Tract & $\begin{array}{c}\text { Gram-positive } \\
\text { Facultative } \\
\text { anaerobic }\end{array}$ & $\begin{array}{l}\text { Eikenella corrodens } \\
\text { Parvimonas micra } \\
\text { Campylobacter showae } \\
\text { Eubacterium } \\
\text { saburreum }\end{array}$ \\
\hline
\end{tabular}

produced a smaller decrease of endotoxins, probably because it is a single-file system. The Genius system consists of 3 files, 1 of them for previous enlargement of the entrance of the canal with a rotating file of 0.08 taper, which facilitates the insertion of other instruments as well as a better penetration of irrigating solutions into the middle and apical thirds. Consequently, the debris formed during instrumentation are easily removed when reciprocating files of the Genius system are used, thus favoring the elimination of microorganisms. This mechanism may contribute to a better cleaning of the root canal system.

When evaluating the association of microbiota with signs and symptoms reported by the patients, the results showed a relationship between $P$. nigrescens (a strictly anaerobic gram-negative bacterium) and spontaneous pain, which corroborates previous investigations $(17,29,30)$. Tenderness to percussion was directly related to the presence of $P$. gingivalis (gram-negative), $P$. nigrescens (gram-negative), V. parvula (gram-negative), $C$. sputigena (gram-negative), and E. saburreum (gram-positive). Gomes et al (31) also reported an association between $P$. gingivalis and tenderness to percussion, presuming that this bacterium has a high virulence factor and pathogenicity frequently related to the presence of periapical abscesses. In addition, the authors also associated gram-negative bacteria with acute endodontic infections (32) although in the present study anaerobic gram-positive bacteria (E. saburreum) were also associated with the presence of a sinus tract and tenderness to percussion. Previous studies have found the same association between gram-positive bacteria and a sinus tract $(33,34)$.

The results found in the present study show that biomechanical preparation performed with rotary, reciprocating, and hybrid systems in association with $2.5 \% \mathrm{NaOCl}$ significantly reduces LPS levels. Also, microorganisms and endotoxins are more likely to be reduced when systems with a greater number of instruments are used, which requires a higher frequency of irrigation during biomechanical preparation. Supporting this point, van der Sluis et al (35) showed that intermittent irrigation causes a refreshment of the irrigant, thus aiding in the removal of dentinal debris.

In conclusion, biomechanical preparation was effective in the reduction of microorganisms and endotoxins although these were not completely removed from the root canal. Also, it was verified that signs and symptoms were associated to the presence of gram-negative and gram-positive anaerobic microorganisms.

\section{Acknowledgments}

The authors thank Dru Renato Miotto Palo for his valuable technical assistance.

Supported by the Brazilian agencies FAPESP (grant nos. 2014/ 25789-9 and 2015/05397-1).

The authors deny any conflicts of interest related to this study.

\section{References}

1. Nair PN, Henry S, Cano V, Vera J. Microbial status of apical root canal system of human mandibular first molars with primary apical periodontitis after "one-visit" endodontic treatment. Oral Surg Oral Med Oral Pathol Oral Radiol Endod 2005; 99:231-52.

2. Siqueira JF Jr, Rocas IN, Alves FR, Santos KR. Selected endodontic pathogens in the apical third of infected root canals: a molecular investigation. J Endod 2004;30: 638-43.

3. Sakamoto M, Rocas IN, Siqueira JF Jr, Benno Y. Molecular analysis of bacteria in asymptomatic and symptomatic endodontic infections. Oral Microbiol Immunol 2006;21:112-22

4. Xing H, Taguchi Y, Komasa S, et al. Effect of Porphyromonas gingivalis lipopolysaccharide on bone marrow mesenchymal stem cell osteogenesis on a titanium nanosurface. J Periodontol 2015;86:448-55.

5. Torabinejad M, Eby WC, Naidorf IJ. Inflammatory and immunological aspects of the pathogenesis of human periapical lesions. J Endod 1985;11:479-88.

6. Cardoso FG, Ferreira NS, Martinho FC, et al. Correlation between volume of apical periodontitis determined by cone-beam computed tomography analysis and endotoxin levels found in primary root canal infection. J Endod 2015;41:1015-9.

7. Bystrom A, Sundqvist G. Bacteriologic evaluation of the efficacy of mechanical root canal instrumentation in endodontic therapy. Scand J Dent Res 1981;89:321-8.

8. Peters OA. Current challenges and concepts in the preparation of root canal systems: a review. J Endod 2004:30:559-67.

9. Burklein S, Hinschitza K, Dammaschke T, Schafer E. Shaping ability and cleaning effectiveness of two single-file systems in severely curved root canals of extracted teeth: Reciproc and WaveOne versus Mtwo and ProTaper. Int Endod J 2012;45: 449-61.

10. Yared G. Canal preparation using only one Ni-Ti rotary instrument: preliminary observations. Int Endod J 2008;41:339-44.

11. Robinson JP, Lumley PJ, Cooper PR, et al. Reciprocating root canal technique induces greater debris accumulation than a continuous rotary technique as assessed by 3-dimensional micro-computed tomography. J Endod 2013;39:1067-70.

12. Moller AJ. Microbiological examination of root canals and periapical tissues of human teeth. Methodological studies. Odontol Tidskr 1966;74(Suppl):1-380.

13. Socransky SS, Haffajee AD, Smith C, et al. Use of checkerboard DNA-DNA hybridization to study complex microbial ecosystems. Oral Microbiol Immunol 2004;19: 352-62.

14. Kundel HL, Revesz G. Lesion conspicuity, structured noise, and film reader error. AJR Am J Roentgenol 1976;126:1233-8.

15. Marmary Y, Koter T, Heling I. The effect of periapical rarefying osteitis on cortical and cancellous bone. A study comparing conventional radiographs with computed tomography. Dentomaxillofac Radiol 1999;28:267-71.

16. Siqueira JF Jr, Rocas IN, Lopes HP. Patterns of microbial colonization in primary root canal infections. Oral Surg Oral Med Oral Pathol Oral Radiol Endod 2002; 93:174-8.

17. Gomes BP, Pinheiro ET, Gade-Neto CR, et al. Microbiological examination of infected dental root canals. Oral Microbiol Immunol 2004;19:71-6.

18. Ferreira NS, Martinho FC, Cardoso FG, et al. Microbiological profile resistant to different intracanal medications in primary endodontic infections. J Endod 2015; 41:824-30.

19. Ciantar M, Gilthorpe MS, Hurel SJ, et al. Capnocytophaga spp. in periodontitis patients manifesting diabetes mellitus. J Periodontol 2005;76:194-203.

20. Desai SS, Harrison RA, Murphy MD. Capnocytophaga ochracea causing severe sepsis and purpura fulminans in an immunocompetent patient. J Infect 2007;54:e107-9.

21. Kaplan A, Kaplan CW, He X, et al. Characterization of aid1, a novel gene involved in Fusobacterium nucleatum interspecies interactions. Microb Ecol 2014;68:379-87.

22. Kaplan CW, Lux R, Haake SK, Shi W. The Fusobacterium nucleatum outer membrane protein RadD is an arginine-inhibitable adhesin required for inter-species adherence and the structured architecture of multispecies biofilm. Mol Microbiol 2009; $71: 35-47$.

23. Ahn SH, Song JE, Kim S, et al. NOX1/2 activation in human gingival fibroblasts by Fusobacterium nucleatum facilitates attachment of Porphyromonas gingivalis. Arch Microbiol 2016;198:573-83.

24. Enersen M, Nakano K, Amano A. Porphyromonas gingivalis fimbriae. J Oral Microbiol 2013;5. 
25. Li X, Kolltveit KM, Tronstad L, Olsen I. Systemic diseases caused by oral infection. Clin Microbiol Rev 2000;13:547-58.

26. Zehnder M, Belibasakis GN. On the dynamics of root canal infections-what we understand and what we don't. Virulence 2015;6:216-22.

27. Siqueira JF Jr, Rocas IN, Souto R, et al. Checkerboard DNA-DNA hybridization analysis of endodontic infections. Oral Surg Oral Med Oral Pathol Oral Radiol Endod 2000;89:744-8.

28. Marinho AC, Martinho FC, Goncalves LM, et al. Does the Reciproc file remove root canal bacteria and endotoxins as effectively as multifile rotary systems? Int Endod J 2015;48:542-8.

29. Jacinto RC, Gomes BP, Ferraz CC, et al. Microbiological analysis of infected root canals from symptomatic and asymptomatic teeth with periapical periodontitis and the antimicrobial susceptibility of some isolated anaerobic bacteria. Oral Microbiol Immunol 2003;18:285-92.

30. Gomes BP, Drucker DB, Lilley JD. Associations of specific bacteria with some endodontic signs and symptoms. Int Endod J 1994;27:291-8.
31. Gomes BP, Montagner F, Jacinto RC, et al. Polymerase chain reaction of Porphyromonas gingivalis, Treponema denticola, and Tannerella forsythia in primary endodontic infections. J Endod 2007;33:1049-52.

32. Nobrega LM, Montagner F, Ribeiro AC, et al. Molecular identification of cultivable bacteria from infected root canals associated with acute apical abscess. Braz Dent J 2016;27:318-24.

33. Signoretti FG, Endo MS, Gomes BP, et al. Persistent extraradicular infection in root-filled asymptomatic human tooth: scanning electron microscopic analysis and microbial investigation after apical microsurgery. J Endod 2011;37: $1696-700$.

34. Sassone LM, Fidel R, Faveri M, et al. Microbiological evaluation of primary endodontic infections in teeth with and without sinus tract. Int Endod J 2008;41: $508-15$.

35. van der Sluis LW, Vogels MP, Verhagen B, et al. Study on the influence of refreshment/activation cycles and irrigants on mechanical cleaning efficiency during ultrasonic activation of the irrigant. J Endod 2010;36:737-40. 